1-h feeding period. Having activity wheel rats feed in their home cage environment was an experimental operation designed to reduce this hypothetical novelty stress. However, this operation failed to alleviate the feeding depression effect. Activity rats feeding in the activity wheel apparatus ate approximately the same amount of food as controls. Only the activity rats feeding in their home cage ate less than control animals. This effect cannot be attributable to differential handling, since all animals were handled for the same amount and number of times. Evidently novelty, as explored by the present study does not contribute significantly to the development of the activity-stress ulcer.

\section{REFERENCES}

Barboriak, J. J., \& Knoblock, H. W. Gastric lesions in food-restricted young rats. Proceedings of the Society of Experimental Biology \& Medicine, 1972, 141, 830-832.

Paré, W. P. The influence of food consumption and running activity on the activity-stress ulcer in the rat. American Journal of Digestive Diseases, 1974, in press.

Paré, W. P., \& Houser, V. P. A ctivity and food-restriction effects on gastric glandular lesions in the rat: The activity-stress ulcer. Bulletin of the Psychonomic Society, 1973, 2, 213-214.

Routtenberg A. "Self-starvation" of rats living in activity wheels: Adaptation effects. Journal of Comparative \& Physiological Psychology, 1968, 66, 234-238.

Routtenberg, A., \& Kuznesof, A. W. Self-starvation of rats living in activity wheels on a restricted feeding schedule. Journal of Comparative \& Physiological Psychology, 1967, 64, 414-421.

(R eceived for publication August 27, 1974.)

\title{
The effect of amygdalectomy on long-term retention of an undertrained classically conditioned fear response*
}

\author{
MELVIN L. GOLDSTEIN $\dagger$ \\ Indiana University at Kokomo, Kokomo, Indiana 46901
}

\begin{abstract}
Rats trained in the classical conditioning fear response were subjected to amygdalectomy $24 \mathrm{~h}$ after conditioning and were tested for retention 4 days and 4-7 weeks postoperatively. The results of the experiment indicated that amygdalectomy disrupted the intermediate and long-term retention of the classically conditioned fear response. There was no recovery of performance after the amygdalectomy. The experiment confirms previous reports of retention deficits after amygdalectomy in undertrained Ss, but does not corroborate previous reports of recovery of function, with additional training, after amygdalectomy.
\end{abstract}

Brady, Schreiner, Geller, and Kling (1954) have reported acquisition deficits in amygdalectomized cats trained in the active avoidance conditioning situation. They did not, however, report any effect of amygdalectomy on retention of a preoperatively learned avoidance task. Horvath (1963) replicated these findings for acquisition and, in addition, reported retention

*The experiment reported in this paper was conducted at the Physiological Psychology Laboratory of Syracuse University. Preparation of this report was supported in part by a supply Preparation of this report was supported in part by the Indiana University Office of Research and Advanced Studies (Grant 26-631-32) and by Summer Faculty Fellow ships awarded by Indiana University.

+Charles Borneman. Jr. made the drawings for publication. Rita Martin typed the manuscript. The writer wishes to express hita Martin typed the manuscript. The writer wishes to exprestion to his wife Daidee for her patience during the preparation of this report and to William L. Stoller for a critical reading of the manuscript. deficits in cats after amygdalectomy. Fonberg, Brutkowski, and Mempel (1962) have reported that, in dogs, an incompletely learned classical defensive CR was disrupted by amygdalectomy but recovered after additional training. Amygdalectomy had no effect, however, on the retention of an overtrained avoidance response. Thatcher and Kimble (1966) have reported that preoperatively overtrained rats showed little or no retention deficit of an avoidance response after bilateral amygdalectomy, while animals trained to criterion and given no overtraining showed a marked retention deficit.

The integrity of the amygdaloid complex is, presumably, essential for the retention of fear-motivated behavior in cats, rats, and dogs. Judging from the 
experiments of Fonberg, Brutkowski, and Mempel (1962) and Thatcher and Kimble (1966) the amount of preoperative training is an important determiner of the effect of amygdalectomy on retention.

The purpose of the present experiment was to extend these findings to a study of the effects of amygdalectomy on the long-term retention of an incompletely learned classically conditioned fear response. The conditioning technique used in the present experiment is an alternative to avoidance conditioning. It is the acquired drive, or classically conditioned fear response, originated by Miller (1948), and developed by McAllister and McAllister (1971) and Goldstein (1960). The procedure provides for the rapid acquisition of a hurdle-jump resonse based upon the classical conditioning of fear to a compound CS of buzzer and light. In the present experiment, an incompletely learned fear response was interrupted by amygdalectomy, and tests of retention were made 4 days and 4-7 weeks after the operation.

\section{METHOD}

\section{Experimental Design}

The general plan of the experiment was to condition groups of rats with the classically conditioned fear response at two levels of UCS intensity, with three CS-UCS pairings, wait $24 \mathrm{~h}$, subject the animals to either bilateral amygdalectomy or cortical control operations, and then test retention of the response 4 days later and 4-7 weeks later. The performance latencies of the amygdalectomized animals were compared with those of the operated controls by means of the analy sis of variance (Edwards, 1960).

Eight animals were conditioned with a medium UCS intensity, and eight animals with a high UCS intensity. After $24 \mathrm{~h}$, the two groups were subdivided and appropriate lesions were placed in the amygdaloid complex $(\mathrm{N}=4 /$ grp $)$ or parietal cortex $(\mathrm{N}=$ 4/group). Postoperative retention tests were conducted 4 days and 4-7 weeks later.

\section{Subjects}

The Ss were 16 naive male hooded rats obtained from the colony maintained by the Psychology Department of Syracuse University. They ranged in age from 150 to 180 days at the start of the experiments. Their weights ranged from $400-480 \mathrm{~g}$.

\section{Apparatus}

The apparatus has been described in detail in an earlier report (Goldstein, 1960). Essentially, it consisted of a two-compartment box. One compartment was a black conditioning chamber with a grid floor; the other compartment was a black "safe" chamber with a wooden floor. The two compartments were separated by a guillotine-type door. The compound CS was a buzzer and a light. The UCS was a 60-cycle ac current conducted to the grid through a 250,000 -ohm series resistor. It was a 1-sec shock of $150 \mathrm{~V}(.5 \mathrm{~mA})$ or $790 \mathrm{~V}$ $(2.6 \mathrm{~mA})$. These were the "medium" and "high" UCS intensities used.

\section{Procedure}

Each $\mathrm{S}$ was conditioned in three stages. During the first phase, $S$ explored both sides of the conditioning box for $10 \mathrm{~min}$. It was then removed from the apparatus and placed into a black holding cage for several seconds. The classical conditioning session began when $S$ was returned to the grid side of the box facing the closed door. CS-UCS were presented after a period of $3 \mathrm{~min}$. The interval between CS-UCS onset was $4 \mathrm{sec}$, UCS duration was $1 \mathrm{sec}$, and CS-UCS were terminated simultaneously $5 \mathrm{sec}$ after CS onset. Each $\mathrm{S}$ was given three CS-UCS pairings at the appropriate shock level with an intertrial interval of $3 \mathrm{~min}$. Five minutes after the last CS-UCS pairing, $\mathrm{S}$ was returned to its home cage for $10 \mathrm{~min}$. The last phase consisted of an adaptation session during which $\mathrm{S}$ again explored both compartments for $10 \mathrm{~min}$. $\mathrm{S}$ was then returned to the home cage for $15 \mathrm{~min}$.

Instrumental hurdle-jump test trials begun immediately afterwards were conducted as follows: $\mathrm{S}$ was placed into the grid-compartment for $10 \mathrm{sec}$, CS was turned on and the door was opened. CS was turned off after $\mathrm{S}$ had jumped across the hurdle. $S$ was permitted to remain in the nongrid compartment for $10 \mathrm{sec}$ and was then removed to the carrying cage where it remained for the 2-min intertrial interval. Hurdle-jump latencies recorded to the nearest $.01 \mathrm{sec}$ served as the response measure.

\section{Surgical Procedures}

Ss were anesthetized with .3-cc Nembutal, placed into a Krieg-Johnson stereotaxic instrument, and an incision was made through the midline of the scalp. Burr holes were drilled through the skull at the appropriate stereotaxic coordinates. Bilateral electrolytic lesions were produced with a 5-mA current of 15-sec duration applied through a fine stainless steel needle insulated with G. E. formvar except for the $.5-\mathrm{mm}$ tip. Stereotaxic coordinates used were as follows, with bregma serving as the zero reference point: Amygdala, AP 1, L 4, D 9; Cortical Control: AP 0, L 4, D 1.

\section{Histological Techniques}

At the completion of the test session, $\mathrm{S}$ was sacrified by etherization, and the brain was removed and preserved in $10 \%$ formalin. Frozen coronal sections 60 micra thick were made in the region of the lesion and stained with cresyl violet.

\section{RESULTS}

Each hurdle-jump latency was converted to a reciprocal and summed over a block of five test trials. The mean reciprocal latency of a block of five test trials was used as the score in a series of analyses of variance.

The effect of amygdalectomy on retention of an incompletely learned classically conditioned fear response is shown in Fig. 1. Amygdalectomy introduced $24 \mathrm{~h}$ after original training yielded poorer performance on the retention tests than for parietal controls. For the high UCS intensity level, the difference in performance between amygdalectomized Ss and parietal controls was significant beyond the .01 level of confidence, $F(1,6)=$ 19.10. For the medium UCS intensity level, the difference between the amygdalectomized and operated controls was just short of significant at the .05 level of confidence, $F(1,6)=5.43$.

The decrements in performance from the preoperative test session to the 4-day postoperative retention session, Test Trials $11-15$ vs $21-25$ (Figure 1), were significant beyond the .01 level of confidence for the medium UCS intensity amygdalectomized group, $F(1,3)=48.50$, and for the high UCS intensity amygdalectomized Ss, $F(1,3)$ $=238.00$. The decrement was not significant for the 


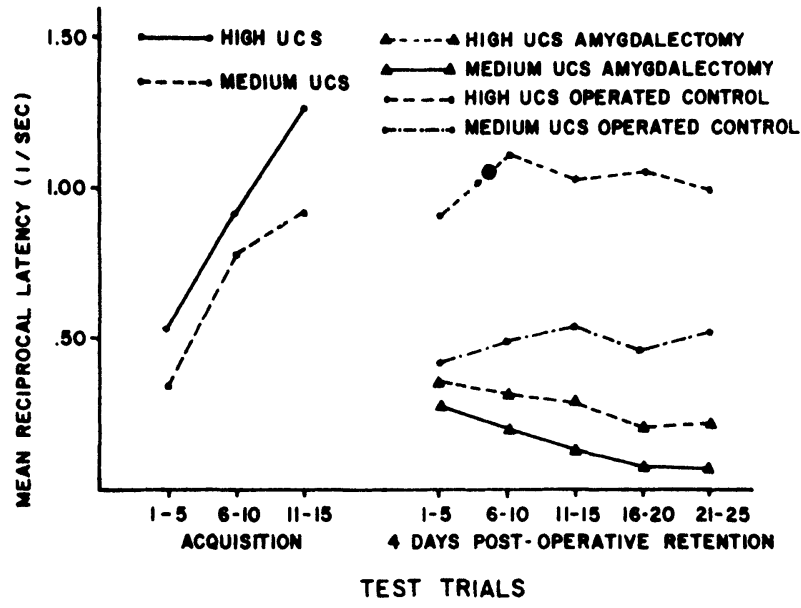

Fig. 1. Preoperative and postoperative performance functions on the conditioned fear test.

medium UCS intensity parietal Ss, $F(1,3)=3.20$. The decrement in performance from the preoperative to the postoperative day for the high UCS intensity parietal lesioned Ss was significant at the .05 level of confidence, $F(1,3)=10.43$. These $F$ tests were calcualted for the differences between Test Trials $11-15$ on the preoperative test and Test Trials 21-25 on the first postoperative retention test.

There were no significant changes in retention performance from the 4-day postoperative test to the long-term (4-7 weeks) postoperative test for the high UCS intensity amygdalectomized Ss, $\mathrm{F}(1,3)=.50$, for the medium UCS intensity amygdalectomized Ss, $F(1,3)$ $=1.00$, or for the high UCS intensity parietal controls, $\mathrm{F}(1,3)=.40$, or for the medium UCS intensity parietal controls, $F(1,3)=7.50$. These $F$ tests were calculated for the differences between Test Trials 21-25 on the first postoperative retention test and Test Trials 11-15 on the second postoperative retention test.

\section{DISCUSSION}

The results of the present experiment indicate that amygdalectomy disrupts the retention of an incompletely learned classically conditioned fear response, as indicated by intermediate and long-term postoperative retention tests. The amygdaloid complex is, therefore, essential for the long-term retention of a classically conditioned fear response. The classically conditioned fear response, in the present experiment, was incompletely learned in the sense that the preoperative performance functions did not reach asymptote.

The finding that the performance deficit in amygdalectomized rats persists for as long as 1 month would suggest that the deficit is associational rather than motivational. The conclusion concerning the involvement of the amygdaloid complex in fear-motivated retention does not, of course, exclude from consideration the possible influence on retention of other limbic structures such as the septal nucleus or the hippocampus.

The findings of the present experiment confirm the previous reports of Thatcher and Kimble (1966) and Fonberg, Brutkowski, and Mempel (1962) of retention deficits after amygdalectomy in undertrained Ss, but do not corrobrate the findings of Fonberg, Brutkowski, and Mempel (1962) of recovery of performance after amygdalectomy. The amygdalectomized animals, in the present experiment, showed no recovery of performance after 4-7 weeks postoperatively.

The results of the present experiment cannot be explained by a general "forgetting" effect, rather than by a retention deficit induced by amygdalectomy, since unpublished work has shown that, in unoperated rats trained in the acquired drive task with the high UCS intensity, the classically conditioned fear response will persist for as long as one week. Some forgetting of acquired fear does, however, occur after $48 \mathrm{~h}$ in normal rats trained with the medium UCS intensity (McAllister \& McAllister, 1968).

Additional experiments are needed to test the effect of varying the consolidation interval, i.e., the time between preoperative training and the amygdalectomy, on long and short term retention in completely trained Ss. Uretsky and McCleary (1969) have recently done such an experiment for the hippocampus. Experiments are also needed to determine whether reconditioning after the 1 month retention test will reinstate the conditioned fear response.

\section{SUMMARY}

Rats trained in the classical conditioning fear response were subjected to amygdalectomy $24 \mathrm{~h}$ after conditioning and were tested for retention 4 days and 4-7 weeks postoperatively. The results of the experiment indicated that amygdalectomy disrupted the intermediate and long-term retention of the classically conditioned fear response. There was no recovery of performance after the amygdalectomy. The experiment confirms previous reports of retention deficits after amygdalectomy in undertrained Ss but does not corroborate previous reports of recovery of function, with additional training, after amygdalectomy.

\section{REFERENCES}

Brady, J. V., Schreiner, L., Geller, I., \& Kling, A. Subcortical mechanisms in emotional behavior: The effect of rhinencephalic injury upon the acquisition and retention of a conditioned avoidance response in cats. Journal of Comparative \& Physiological Psychology, 1954, 47, 179-186.

Edwards, A. L. Experimental design in psychological research. New York: Holt, R inehart, \& Winston, 1960.

Fonberg, E., Brutkowski, S., \& Mempel, E. Defensive conditioned reflexes and neurotic motor reactions following amygdalectomy in dogs. Acta Biologie Experimental, Warsaw 1962, 22, 51-57.

Goldstein, M. L. Acquired drive strength as a joint function of shock intensity and number of acquisition trials. Journal of Experimental Psychology, 1960, 60, 349-358.

Horvath, F. E. Effects of basolateral amygdalectomy on three types of avoidance behavior in cats. Journal of Comparative \& Physiological Psychology, 1963, 56, 380-389.

Miller, n. E. Studies of fear as an acquirable drive: I. Fear as motivation and fear reduction as reinforcement in the learning of new responses. Journal of Experimental Psychology, 1948 , 38, 89-101.

McAllister, D. E., \& McAllister, W. R. Forgetting of acquired fear. Journal of Comparative \& Physiological Psychology, $1968,65,352-355$.

McAllister, W. R., \& McAllister, D. E. Behavioral measurement of conditioned fear. In Brush, F. R. (Ed.) Aversive conditioning and learning. New York: Academic Press, 1971.

Thatcher, R. W., \& Kimble, D. P. Effect of amygdaloid lesions on retention of an avoidance response in overtrained and nonovertrained rats. Psychonomic Science, 1966, 6, 9-10.

Uretsky, E. \& McCleary, R. A. Effect of hippocampal isolation on retention. Journal of Comparative \& Physiological Psychology, 1969, 68, 1-8.

(Received for publication August 21, 1974.) 